\title{
A vida escrava portas adentro: uma incursão as senzalas o Engenho de São Joaquim, Goiás, século XIX
}

\author{
Marcos André Torres de Souza \\ Bolsista de pós-doutorado do CNPq; Museu Nacional / UFRJ \\ "A door is most meaningfully disclosed when we area standing before it. To be \\ before a door is in its deepest significance to be a sensitive attendant waiting \\ for the manifestation of the other, for the appearance of the real. Our ritual of \\ knocking on the door is the embodiment of respectful waiting or pause; it is not \\ an empty gesture. With this respectful hesitation at a door demarcating difference, \\ we provoke a life of community, of being together with others-indifference. We \\ celebrate the vital difference between self and other and thereby make possible a \\ meeting. At the doorway, we respectfully wait for the other. In its purest mythic \\ form, the person before the door is the stranger who journeys from afar, who so- \\ licits the real, who asks for admission. The dweller offers this stranger hospitality, \\ and the door becomes the meeting place of host and guest, of person and world"1.
}

\section{Introdução}

No campo da Arqueologia Histórica, tem sido comum os pesquisadores apontarem o caráter 'democrático' do registro arqueológico. Isso porque, em nossas escavações, estamos em condições de recuperar artefatos associados a diferentes grupos de pessoas, incluindo ricos e pobres, livres e escravos, homens e mulheres, adultos e crianças, e assim por diante. $O$ registro arqueológico permite acesso direto à cultura material utilizada - e muitas vezes produzida - pelos mais diferentes segmentos da sociedade. Por meio do seu estudo, estamos em condições de melhor compreender processos culturais e práticas sociais pretéritas, ainda que tenhamos diante de nós o desafio de contar apenas com remanescentes incompletos do passado que procuramos explicar. 
Apesar do potencial da arqueologia para a compreensão de práticas sociais associadas a grupos que não puderam registrar sua própria história, ainda existem muitas lacunas a ser preenchidas. Esse é o caso da vida escrava, que vem sendo pesquisada por um numero ainda muito limitado de arqueólogos, a despeito do imenso peso demográfico e social que teve a escravidão no Brasil (ver um balanço recente desses estudos em Singleton e Souza ${ }^{2}$ ).

Neste artigo, proponho avançar na discussão acerca da escravidão no Brasil, tomando como ponto de partida à análise da cultura material escavada no interior de um conjunto de senzalas oitocentistas. Essa análise se baseia em dados provenientes do Engenho de São Joaquim (atual Fazenda Babilônia), um engenho datado de 1800 e que ainda tem sua sede preservada. Esse engenho, situado em Meia Ponte (atual Pirenópolis), Goiás, pertenceu a Joaquim Alves, o mais rico escravocrata da região. Embora não se saiba ao certo o número de escravos que viviam nesse engenho na primeira metade do século XIX, é possível se obter uma aproximação a partir do inventário de Alves, datado de 1954. A essa época, o engenho contava com 106 escravos, sendo possível que esse número tenha sido superior entre as décadas de 1810 e 1830, quando o engenho estava no auge da sua atividade. As comunidades escravas que aí viveram em meados do século XIX eram compostas majoritariamente por escravos nascidos no Brasil e do sexo masculino. Os africanos tinham idade igual ou superior a 70 anos e foram, possivelmente, adquiridos no período de formação inicial do plantel, no começo da ocupação do engenho (Inventário de Joaquim Alves de Oliveira, 1854, maço 14, n 266; Arquivo Cartorial de Família de Pirenópolis). Ao passar por inúmeras transferências entre os herdeiros de Alves, a propriedade viu seu plantel de escravos declinar drasticamente. Em 1864, contava com 72 indivíduos. Poucos anos depois restavam apenas 51 indivíduos (Inventário de Joaquim da Costa Teixeira, 1864, maço 14, $\mathrm{n}^{\circ}$ 266; Arquivo Cartorial de Família de Pirenópolis).

$\mathrm{Na}$ minha análise, procuro compreender os modos pelos quais as relações sociais passadas no interior das senzalas se estabeleceram. Para isso, tomo como ponto de partida o espaço construído dessa propriedade e o perfil do seu proprietário.

\section{Maracanan}




\section{O Engenho de São Joaquim e seu proprietário}

Joaquim Alves possuía a maior fortuna de Goiás na primeira metade do século XIX, tendo sido ele senhor de muitos escravos e negócios. Como comerciante, vendia aguardente e açúcar para o mercado local, exportava algodão para o Rio de Janeiro e importava produtos europeus e escravos para Goiás e Mato Grosso. Fez também carreira pública, exercendo inúmeros cargos políticos, militares e seculares. Foi ele também o responsável pela criação do primeiro jornal goiano, A Matutina Meiapontense, fundada em 1833. Ele era considerado na comunidade um visionário e seu engenho foi, de certa forma, um reflexo disso ${ }^{3}$.

A arquitetura do engenho era inovadora para os referenciais locais. Nessa propriedade, ele combinou certos elementos tradicionais, como, por exemplo, uma faixa frontal inspirada pela casa bandeirista, composta por uma capela, varanda e quarto de hóspedes, e cuja origem remontava ao século XVII, mas, no interior do edifício, criou espaços complexos e hierarquizados. Esse edifício contava com uma faixa publica, uma de convívio doméstico, uma zona destinada aos escritórios e área produtiva, onde ficava o engenho de cana e caldeirões, que foi trazido para o corpo do edifício. Um aspecto importante na construção dessa sede e da hierarquização dos seus espaços é que ela foi criada a fim de favorecer a supervisão do trabalho escravo, permitindo um maior controle sobre eles. A partir da sede, o proprietário podia observar, da varanda, o que acontecia no terreiro e nas senzalas, que ficavam à sua frente. Podia também observar o que acontecia no engenho de cana e caldeirões, que ficavam situados no próprio corpo da sede $\mathrm{e}^{4}$.

Esse interesse em maximizar o controle da vida escrava estendeu-se à arquitetura das senzalas que não seguiam o costume local de organizarem-se como arranjos de pequenas cabanas. Nesse engenho, as habitações escravas eram compostas por pavilhões mandados construir por Alves defronte à sede 5 .

Atualmente, não existem remanescentes em superfície das senzalas do engenho. Todavia, por meio da análise combinada das fontes documentais e arqueológicas, foi possível a compreensão da sua localização exata e feição. As senzalas eram formadas por dois longos pavilhões com as dimensões aproximadas de 150 e 50 metros, formando um ' $\mathrm{L}$ ' invertido defronte 
à sede e organizados em torno de um pátio central. Embora não tenham sido encontrados vestígios de divisões internas - provavelmente em função do emprego, para esse fim, de materiais que não deixaram assinatura arqueológica, informantes que viram, no começo do século XX, as ruínas desse conjunto, disseram que os pavilhões eram divididos em cubículos com uma porta e uma janela cada. Considerando que a profundidade dos dois edifícios era de cinco metros, é possível que eles fossem divididos em cubículos de 5,0 x 5,0 metros ${ }^{6}$.

Segundo os diversos viajantes que passaram pela propriedade na primeira metade do século XIX, Alves preocupava-se com o bem esta dos seus

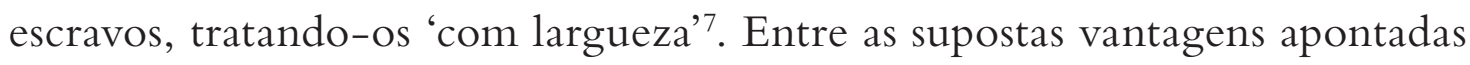
por esses cronistas, havia a moradia, que era mandada construir pelo próprio Alves.

Ainda que pareça vantajoso contar com um conjunto de habitações construído pelo proprietário do engenho, isso, na verdade, envolvia certos prejuízos. Isso porque os escravos não contavam com o que Ingold ${ }^{8}$ definiu como 'engajamento prático'. Fugia do seu controle a decisão de escolher a forma e feição das suas habitações, bem como o uso de técnicas ou materiais particulares. Eles também não podiam lançar mão de estratégias que lhes permitia escapar do controle e da ordem impostos pelo proprietário. Quando viviam em uma pequena vila de cabanas por eles construídas, os escravos, tinham inúmeras possibilidades em termos de áreas de circulação. Tinham melhores chances também para criar pequenos domínios de área privada e setores que escapavam ao campo supervisão visual dos senhores e feitores, já que esse tipo de organização podia criar áreas cegas para o supervisor, tal como, por exemplo, acontecia em algumas plantations do Caribe 9 . Nas senzalas pavilhão, por outro lado, os escravos viam-se encapsulados. Contavam com pouquíssimas áreas de circulação e com poucas possibilidades para gerenciar suas áreas de convivência. Viam-se ainda muito mais expostos à supervisão visual.

Esse quadro exemplifica uma situação comum em plantéis mantidos por escravocratas como Joaquim Alves. Ao mesmo tempo em que homens como Alves promoviam melhores condições de vida aos seus escravos, aumentavam o controle sobre eles, incluindo a supervisão do seu trabalho e das atividades cotidianas a partir do seu local de habitação ${ }^{10}$.

\section{Maracanan}


Em um cenário de controle extremo tal como o do Engenho de São Joaquim, uma pergunta que se coloca é como se passava a vida no interior das senzalas. Mostra-se relevante entender como os escravos fizeram frente ao controle e disciplina impostos pelo seu senhor. Não só isso, importa também compreendermos os mecanismos pelos quais eles estabeleceram e reproduziram rotinas e práticas sociais, potencialmente identificadas com expectativas próprias. Nas Ciências Sociais e, em particular, na historiografia brasileira, há muito foi descartada a imagem do escravo resignado e passivo como modelo, expresso na emblemática imagem do 'pai João' retratada por Eduardo Silva (1989). Compreender a natureza e as implicações das transgressões, da resistência cotidiana ou da criação de espaços próprios nos induz a explorar os intricados mecanismos ligados às práticas cotidianas escravas, e em boa medida, as forma como elas foram estruturadas. A discussão que se segue propõe-se a explorar essas questões, tomando como referencia a cultura material por eles utilizada e, em alguns casos, produzida, encontrada em dois setores escavados das senzalas do Engenho de São Joaquim.

'Desordem positiva': os artefatos encontrados no interior das senzalas

Durante a pesquisa arqueológica no engenho, foram escavadas duas áreas interiores das senzalas, denominadas áreas 11 e 12 (Figura 1). Em ambas, foi encontrada uma camada de solo com uma espessura média de apenas sete centímetros e que concentrava todo o material encontrado. Essa camada corresponde ao nível do piso das senzalas, que era formado por terra batida. Os artefatos encontrados estavam distribuídos de forma desigual, concentrando-se em partes específicas. $\mathrm{Na}$ área 11 , ficou evidente que essa concentração se relacionava a uma lente de fogueira, onde provavelmente os escravos que habitavam um dado cubículo se reuniam e desempenhavam um número de atividades cotidianas, o que terminou dando formação a uma área de deposição de refugo arqueológico.

Janeiro | Dezembro 2011 


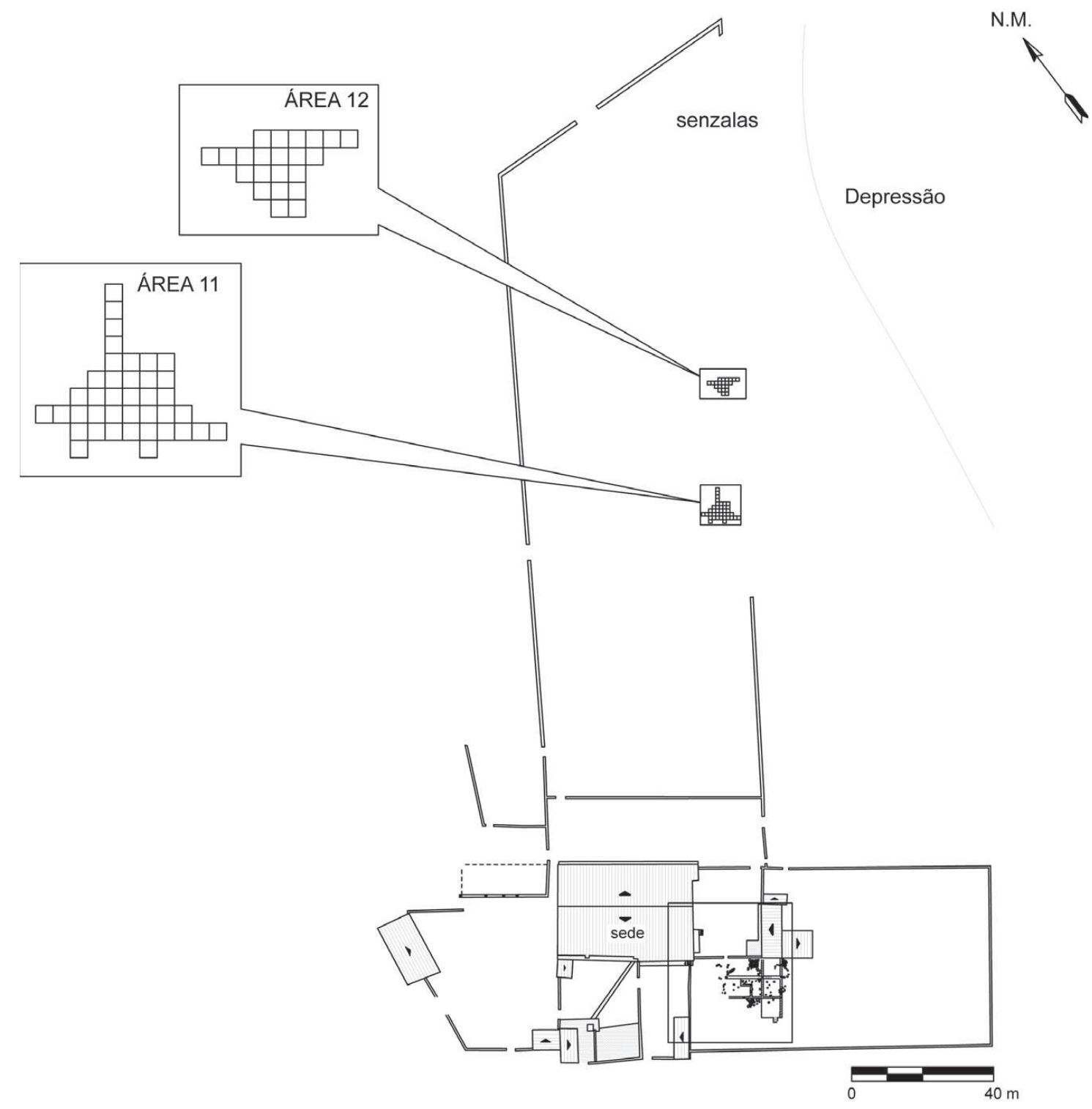

Figura 1: Planta baixa do Engenho de São Joaquim.

O alto número de fragmentos encontrados nas duas áreas pesquisadas é uma evidência importante. Na Área 11, foi encontrada uma média de 77 fragmentos $/ \mathrm{m}^{2}$, descontando-se os materiais construtivos, tais como fragmentos de telha e cravos. Nos pontos onde foi encontrada uma concentração maior de fragmentos, esse número ultrapassou 300 fragmentos/ $\mathrm{m}^{2}$. Na Área 12, o quadro não foi muito diferente, tendo sido encontrada uma média de 61 fragmentos $/ \mathrm{m}^{2}$ e picos de até 250 fragmentos/ $\mathrm{m}^{2}$ nos locais de maior concentração. Nesse cenário, é útil considerar que

\section{Maracanan}


estamos tratando de uma camada com uma espessura que não ultrapassava os oito centímetros.

O alto número de fragmentos encontrados no interior das senzalas é um indicador de intensa atividade cotidiana. Mais ainda, mostra que, no seu interior, era aceita a acumulação de resíduos. Considerando que as senzalas do engenho foram ocupadas por mais de meio século, a presença de um piso de ocupação pouco espesso é um indicador que alguma atividade de manutenção e limpeza era realizada no seu interior. Todavia, e a contar pelas evidências arqueológicas encontradas, isso não era realizado de forma extensiva.

A coexistência dos ocupantes das senzalas do Engenho de São Joaquim com o seu lixo, tinha obviamente, uma base cultural. Em In Small Things Forgotten, Deetz ${ }^{11}$ demonstrou a relação intima que existe entre os modos pelos quais as pessoas lidam com seu lixo e a visão que tem da sociedade. Segundo ele, descartar o lixo constitui-se em um dos nossos mais inconscientes atos. Todavia, está associado a uma ordem profunda das coisas, na qual estamos imersos. O refugo descartado no interior das senzalas do Engenho de São Joaquim não escapou a essa lógica.

Em relatos históricos, geralmente impregnados de eurocentrismo, não são incomuns menções à insalubridade das casas pobres, retratadas como insuportavelmente sujas, empoçadas e enfumaçadas, o que é particularmente válido para as cozinhas, local de atividade por excelência das escravas domésticas $^{12}$. As descrições do interior das senzalas são mais raras, já que só eventualmente preocupavam-se os cronistas em descrever seu interior. Quando as descreviam, o relato não era muito diferente. Esse foi o caso da impressão colhida por Ribeyrolles ${ }^{13}$, que retratou as senzalas do sudeste de meados do século XIX como mal asseadas e infectadas. Na América do Norte, um quadro similar apresentava-se, sugerindo uma base comum para tais práticas. $\mathrm{Na}$ análise de Vlach $^{14}$ sobre as mudanças na arquitetura das habitações escravas americanas durante a primeira metade do século XIX, os senhores descreviam a tendência dos escravos de acumular lixo e sujeira nas suas residências, tanto no solo, quanto nas rachaduras das paredes, onde tendiam a acumular-se toda sorte de objetos, incluindo trapos de tecido, sapatos velhos, peles de animais e penas de galinha.

Uma maneira de deslocar essa discussão além da ótica européia é assumindo que, conforme afirmou Mary Douglas ${ }^{15}$, a sujeira 'está nos olhos de 
quem a vê'. A decisão sobre o que é ou não entendido como sujeira é uma questão relativa e depende de referenciais culturais específicos. Um exemplo que pode aqui ser considerado, permitindo uma reflexão sobre a utilidade e função de se ter o próprio lixo por perto, é o do estudo etnográfico realizado por ${ }^{16}$ sobre os Dogon, que habitam hoje uma parte de Mali, pais do oeste da África. Na sua investigação, ele identificou um gosto especial entre os Dogon pelo que denominou uma 'desordem positiva' nas casas. Para essas comunidades, quanto maior a desordem, melhor. Isso porque a desorganização de uma casa é por eles entendida como 'sinal de vida'. Os detritos, itens varridos e fuligem nas paredes da casa são intencionalmente mantidos, uma vez que indicam prosperidade e longevidade. Costuma-se dizer: 'possa Deus enegrecer o teto de sua casa'. Acredita-se que limpar a fumaça do teto ou as panelas após as refeições, ao contrário, irá trazer escassez e morte. As roupas surradas e rasgadas são também um indicativo de vitalidade, indicando a longevidade do corpo. A sujeira e o suor corporal são percebidos, de forma similar, como associados à vitalidade e intensa atividade cotidiana. Pessoas que se mantêm limpas são, por outro lado, consideradas preguiçosas.

Os Dogon vivem nas imediações da região incluída entre as zonas de floresta, as zonas de savana e o médio rio Níger, principal origem da maioria dos escravos embarcados no oeste da África ${ }^{17}$. Relatos de acúmulo excessivo de 'lixo' são também encontrados entre viajantes que visitaram a África Central, outra região importante de origem dos escravos que vieram para o Brasi1 ${ }^{18}$. É possível, portanto que tal prática tenha uma base cultural, comum a muitos dos escravos que viveram nas Américas. Embora tal afirmação afigure-se, neste momento, apenas como uma possibilidade, pode-se considerar, com um grau maior de confiança, que os escravos do engenho possuíam uma percepção bastante distinta daquilo que no Mundo Moderno se definiu como sujeira.

O comportamento do refugo presente no interior das senzalas adquire ainda maior relevância ao considerar-se que os livres que viviam na propriedade tinham uma percepção muito diferente da que possuíam os seus escravos, a começar por Joaquim Alves. Conforme fizeram questão de assinalar os três viajantes europeus que por lá passaram, reinava na propriedade, 'ordem', 'decência' e 'limpeza'19, uma impressão que em nada

\section{Maracanan}


destoa do comportamento deposicional do material encontrado em áreas externas às senzalas. Contrastando nitidamente com o comportamento encontrado no seu interior, as sondagens realizadas no terreiro situado defronte às senzalas não ultrapassaram o número de 1 fragmento $/ \mathrm{m}^{2}$. Nas áreas posteriores às senzalas, onde se buscou diagnosticar sem sucesso áreas de deposição secundária de refugo, os pontos onde o material se apresentou com densidade um pouco superior, limitou-se a um conjunto de pequenos edifícios nos fundos do pavilhão maior. Em outras sondagens, realizadas nos fundos sul e norte do pavilhão maior, não foram identificados mais que sete fragmentos em toda a área escavada. Convém considerar, refiro-me aqui a um conjunto onde viviam mais de uma centena de escravos, que ocuparam as senzalas desde o ano de 1800 até pelos menos fins da década de 1860. No quintal da sede não foi muito diferente. Aí foram encontrados muito poucos fragmentos referentes à primeira metade do século XIX, estando eles concentrados em pontos de dejeção específicos.

O contraste existente entre o comportamento de deposição do material arqueológico encontrado nas áreas interior e exterior das senzalas é evidente. Enquanto a parte exterior do engenho era mantida limpa, obedecendo a preceitos de ordem e asseio - atributos assinalados pelos viajantes como alvo da preocupação de Alves, o interior das senzalas concentrava um número significativo de dejetos. Considerando a preocupação de Alves com a disciplina e a ordem na propriedade, bem como seu interesse em manter sua escravaria em condições salubres de existência, é possível que a limpeza existente nas áreas exteriores às senzalas fosse imposta. No interior das senzalas, onde o monitoramente das ações possivelmente fugia ao seu controle, essa ordem era peremptoriamente negada. Aí um comportamento diferente parece ter se estabelecido, baseado em um conjunto de referencias estranhos aos que habitavam a sede do engenho.

Sabe-se que em muitas regiões das partes oeste e central da África é comum que a socialização se de em áreas externas, ainda que, em algumas situações, apenas nas estações chuvosas ${ }^{20}$. No Engenho de São Joaquim, onde o ambiente sofria estrito controle por seu proprietário, é possível que os escravos viram-se compelidos a interagir em suas horas de folga, majoritariamente, nas áreas internas das senzalas.

Janeiro | Dezembro 2011 
A diversidade material no interior das senzalas

Os artefatos encontrados no nível do piso das senzalas das duas áreas datam entre 1800 e 1864. Em linhas gerais, eles são bastante semelhantes, tanto em termos quantitativos quanto em termos qualitativos. A única diferença perceptível está nos materiais construtivos, que aparecem em maior densidade na Área 12, e nos artefatos ligados ao preparo, serviço e consumo de alimentos, que têm maior incidência na Área 11 (Tabela 1).

\begin{tabular}{lcccc}
\hline & \multicolumn{2}{c}{ Área } & $\mathbf{1 1}$ & \multicolumn{2}{c}{ Área } & $\mathbf{1 2}$ \\
& $\mathbf{N}$ & $\mathbf{0}$ & $\mathbf{N}$ & $\mathbf{\%}$ \\
\hline Materiais construtivos & 101 & 3,88 & 231 & 18,42 \\
Mobiliário & 1 & 0,04 & 0 & 0,00 \\
Preparo, consumo e serviço de alimentos & 1952 & 74,93 & 732 & 58,42 \\
Restos alimentares & 449 & 17,24 & 192 & 15,31 \\
Ferramentas multifuncionais e/ou recicladas & 29 & 1,11 & 42 & 3,35 \\
Vestuário e adornos & 6 & 0,23 & 5 & 0,40 \\
Itens de devoção & 2 & 0,08 & 0 & 0,00 \\
Armas & 5 & 0,19 & 8 & 0,64 \\
Fumo & 4 & 0,15 & 0 & 0,00 \\
Corte e costura & 0 & 0,00 & 1 & 0,08 \\
Transporte & 19 & 0,73 & 13 & 1,04 \\
Miscelânea / Não determinado & 37 & 1,43 & 30 & 2,39 \\
\hline T = & $\mathbf{2 6 0 5}$ & $\mathbf{1 0 0 , 0 0}$ & $\mathbf{1 2 5 4}$ & $\mathbf{1 0 0 , 0 0}$ \\
\hline
\end{tabular}

Tabela 1: Artefatos encontrados nas duas áreas escavadas nas senzalas, organizados por categorias funcionais.

No que diz respeito aos materiais construtivos encontrados nas áreas 11 e 12, seu percentual é de modo geral baixo. Esses itens misturaram-se com aqueles existentes no nível do piso, possivelmente, após o colapso do edifício e antes que aí se formasse uma nova camada de sedimento. Na área 11, só foram encontrados cravos. Na área 12, além dos cravos, apareceram evidências de que as portas possuíam trancas, incluindo um fragmento de dobradiça de porta, uma peça de fechadura e um fragmento de chave de porta, o que aponta para a possibilidade dos escravos terem a chance de trancarem-se em seus cubículos.

\section{Maracanan}


Os itens de mobiliário são raros. Eles não apareceram na área $11 . \mathrm{Na}$ área 12 essa categoria foi representada apenas por uma pequena dobradiça, provavelmente usada em alguma pequena caixa ou outro item de mobília de dimensões reduzidas. Embora esses dados sugiram uma escassez de mobiliário no interior dessas habitações, é importante considerar que eles, por si só, são insuficientes para essa afirmação, uma vez que os escravos podem ter utilizado peças de mobília feitas de matérias-primas que não deixam assinatura arqueológica, tais como madeira e fibras vegetais.

Dos índices percentuais do material encontrado nas senzalas, predominaram aqueles ligados ao sistema de alimentos. Na Área 11, 73,73\% da amostra é composta por itens usados no preparo, serviço e consumo de alimentos e $17,24 \%$ por restos alimentares (ossos animais). Na Área 12, os valores são de $58,43 \%$ e $15,31 \%$, respectivamente.

No consumo de alimentos, os escravos serviam-se apenas de garrafas que foram sucessivamente enchidas com novos conteúdos, o que é testemunhado por um alto nível de abrasão externos dos recipientes causado pelo uso constante. A exceção foi a de quatro fragmentos pequenos de vidro transparente encontrados na área 11 que compunham copos ou taças. No preparo, consumo e serviço de alimentos, usavam recipientes cerâmicos em profusão. Esse foi o item mais encontrado nas duas áreas, representando 72,02\% da amostra da área 11 e 50,60\% na área 12.

De modo geral, os restos alimentares e o agenciamento de itens industrializados apontam para uma forte base cultural. Entre os ossos (Figura 2), muitos deles apresentam fraturas que sugerem que eles foram quebrados ou perfurados (ao invés de cortados), muitas vezes para a retirada do tutano, prática comum tanto em regiões do oeste da África ${ }^{21}$ quanto em sitos escravos na América do Norte ${ }^{22}$. No grupo dos talheres, foi encontrado apenas o fragmento de uma colher na área 11. Esse quadro é consistente com uma preferência comum no oeste da África, onde, no passado, consumia-se os alimentos com uma colher ou simplesmente com as mãos ${ }^{23}$. As faianças encontradas nas senzalas apontam também uma influência africana no consumo de alimentos, uma vez que, na amostra, predominam as tigelas, cuja preferência pelo uso é comum tanto no oeste da África quanto em outros sítios de contextos escravos no Brasil ${ }^{24}$. 


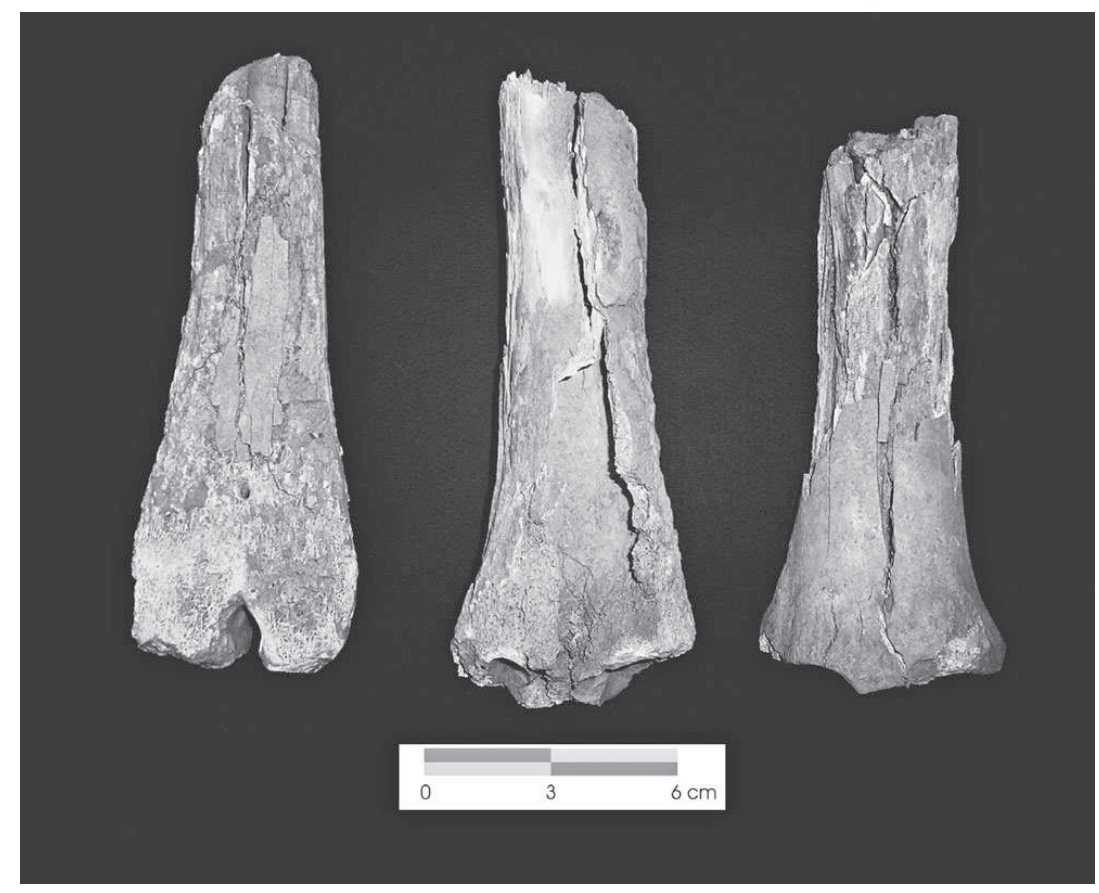

Figura 2: Restos alimentares ósseos provenientes das senzalas. Notar, na peça ao centro, a presença de quebra para retirada do tutano. Nas peças da esquerda e da direita, vê-se quebras na região da diáfise.

As louças apareceram em número muito reduzido nas senzalas. Na área 11 foram encontrados apenas vinte fragmentos $(0,77 \%)$, enquanto na área 12 , doze fragmentos $(0,96 \%)$. Esses índices contrastam com os dos depósitos arqueológicos da sede referentes ao período 1800-1860, onde esse percentual oscilou entre 5 e 18\%. Como é de se supor, os escravos e senhores contavam com possibilidades desiguais para a aquisição de itens em faiança. No que diz respeito ao custo desses objetos, contudo, os dados vão contra o que seria razoável considerar. Isso porque não se verificou a presença de itens de maior valor nas sedes. A Tabela 2 mostra uma comparação entre as louças encontradas nas senzalas e aquelas encontradas nas escavações do quintal da sede referentes ao mesmo período (1800-1860). Essa comparação toma como base a Escala de Miller ${ }^{25}$, um ranking de preços que arranja as louças hierarquicamente, de acordo com seu preço, das mais baratas (não decoradas) até as mais caras (decoradas pela técnica do transfer-printing). Nesse ranking estão embutidos fatores como o custo de produção e custo ao consumidor. Uma modificação por mim empregada na escala de Miller inclui as porcelanas, cujo custo era superior às louças mais caras.

\section{Maracanan}




\begin{tabular}{lccccccccccc}
\hline & \multicolumn{2}{c}{$\begin{array}{c}\text { Não } \\
\text { decoradas }\end{array}$} & \multicolumn{2}{c}{ Minimamente } & \multicolumn{2}{c}{ Pintadas } & \multicolumn{2}{c}{ Transfer } & Porcelana & T(N) \\
& $\mathbf{N}$ & $\mathbf{0}$ & $\mathbf{N}$ & $\mathbf{0}$ & $\mathbf{N}$ & $\mathbf{\%}$ & $\mathbf{N}$ & $\mathbf{\%}$ & $\mathbf{N}$ & $\mathbf{\%}$ & \\
\hline Sede & 38 & 50,00 & 17 & 22,37 & 1 & 1,32 & 18 & 23,68 & 2 & 2,63 & 76 \\
Senzalas & 18 & 56,25 & 4 & 12,50 & 4 & 12,50 & 6 & 18,75 & 0 & 0,00 & 32 \\
\hline
\end{tabular}

Tabela 2: Escala de preços de Miller aplicado às louças encontrados em áreas de deposição de refugo do Engenho de São Joaquim datadas entre 1800 e 1864.

Conforme pode se observar na Tabela 3, existe, nas senzalas, um percentual ligeiramente maior das louças mais baratas disponíveis no mercado: as não decoradas. O que, todavia, pesa na diferença entre as duas amostras é o predomínio de louças minimamente decoradas ou pintadas à mão nas senzalas, cujas cores apresentaram-se em diferentes combinações, e peças em transfer-printing na sede, geralmente impressas no fundo dos pratos em azul com cenas de inspiração oriental e romântica. Considerar essa diferença apenas sob o prisma do preço é insuficiente, isso porque diferenças de status sócio-econômico não parecem ter sido os aspectos determinantes nesse quadro mas sim diferenças culturais. Essa possibilidade foi proposta por Wilkie ${ }^{26}$ que, ao analisar os artefatos recuperados em senzalas de uma propriedade rural na Jamaica, encontrou uma preferência similar àquela encontrada no Engenho de São Joaquim. No caso jamaicano, preferiam os recipientes minimamente decorados ou pintados à mão, cujas decorações apresentavam-se em combinações nas cores marrom, amarelo, laranja e verde, e que formavam motivos geométricos, tais como pontos, ziguezigues, e linhas paralelas. Com isso, opunham-se às louças encontradas na sede da propriedade que, majoritariamente, apresentavam-se em cenas na cor azul, produzidas pela técnica do transfer-printing. Segundo ela, a preferência dos escravos pela decoração encontrada teria sido influenciada pela estética de grupos oriundos da África. Em contextos brasileiros, um caso semelhante foi identificado na região de Mato Grosso, em sítios rurais do século XIX ${ }^{27}$. É possível considerar, portanto, que na escolha para a aquisição dessas louças, os escravos do Engenho de São Joaquim estivessem mais preocupados em utilizar itens que se coadunavam com sua base cultural e não propriamente com os aspectos sócio-econômicos envolvidos na apresentação desses itens. 


\begin{tabular}{|c|c|c|c|c|}
\hline & Área 11 & Área 12 & Área 9 & Total \\
\hline & & & & 54 \\
\hline Raspar & 17 & 37 & 0 & \\
\hline Vidro reciclado & 14 & 33 & 0 & 47 \\
\hline Lítico & 3 & 4 & 0 & 7 \\
\hline Perfurar & 1 & 0 & 0 & 1 \\
\hline Vidro reciclado & 1 & 0 & 0 & 1 \\
\hline Garfo reciclado & 0 & 0 & 1 & 1 \\
\hline Cortar & 1 & 0 & 0 & 1 \\
\hline Vidro reciclado & 1 & 0 & 0 & 1 \\
\hline Instrumentos multifuncionais & 2 & 3 & 0 & 5 \\
\hline Canivete & 0 & 3 & 0 & 3 \\
\hline Faca de ponta & 2 & 0 & 0 & 3 \\
\hline Total & 21 & 40 & 1 & 62 \\
\hline
\end{tabular}

Tabela 3: Artefatos usados para raspar, perfurar e cortar encontrados nas senzalas do engenho e suas proximidades.

A entrada de louças de alto custo nas residências escravas, convém assinalar, não é inusitada, tendo sido notada por arqueólogos nas Américas desde a década de $1970{ }^{28}$. Para a entrada desses itens na esfera doméstica, três possibilidades se apresentam. Uma primeira, seria sua aquisição em segunda mão. Quando os senhores tivessem, por exemplo, seus aparelhos de chá e jantar danificados, tornando-se, assim, incompletos, podiam doá-los aos seus escravos. Uma segunda possibilidade envolveria sua aquisição no mercado por meio da criação de uma economia informal entre os escravos, que podiam comprá-las de forma avulsa. Uma ultima possibilidade, era o furto.

Uma das mais discutidas formas de adquirir esses itens era por meio da venda de excedentes das roças cultivadas pelos escravos. Nas duas últimas décadas, historiadores têm encontrado evidências concretas desse tipo de comercialização ${ }^{29}$. No caso do Engenho de ao Joaquim, esse parece ter sido o caso. Os viajantes que por lá passaram ${ }^{30}$ informaram que era facultado aos escravos dessa propriedade terem suas próprias roças, bem como a venda desses itens no próprio engenho, para o proprietário. Dessa forma, é possível que a entrada de faianças nas senzalas tenha se dado, ao menos em parte pela compra de peças por alguns indivíduos.

\section{Maracanan}


Embora a oportunidade criada para Alves para a comercialização de itens na propriedade possa ser entendida como uma forma adicional de controle, reafirmando a relação de dominação por ele exercida, tinha importantes conseqüências práticas, uma vez que situações dessa ordem ofereciam, conforme assinalaram Berlin e Morgan ${ }^{31}$, novas bases materiais para a criação de cultural próprias, o que se mostra adequado para o caso de São Joaquim, uma vez que, conforme assinalei acima, os escravos estavam optando pela aquisição de louças com decorações distintas das dos proprietários.

A análise de itens ligados a armamentos oferece uma evidência complementar da criação de uma economia informal no engenho. Nas duas áreas investigadas, foram encontrados diversas peças ligadas a armamentos, como pederneiras, balas de chumbo e peças de armas (Figura 3). O uso de armas de fogo, uma questão polêmica no período colonial, chegou a ser proibido entre os escravos em algumas regiões brasileiras devido ao temor de sedição ${ }^{32}$. No Engenho de São Joaquim, onde seu proprietário permitia aos escravos a criação de uma economia informal em beneficio próprio, é possível que as regras quanto ao uso de armas tenham sido afrouxadas. Ao invés de se constituírem em instrumentos de defesa pessoal, o que, naturalmente, desencadearia a repressão ao seu uso, é bem possível que elas tenham sido utilizadas para complementação da dieta alimentar ou para a comercialização informal de carne e couros de animais silvestres, que se constituíam em um gênero de exportação importante em Goiás na primeira metade do século XIX ${ }^{33}$. 


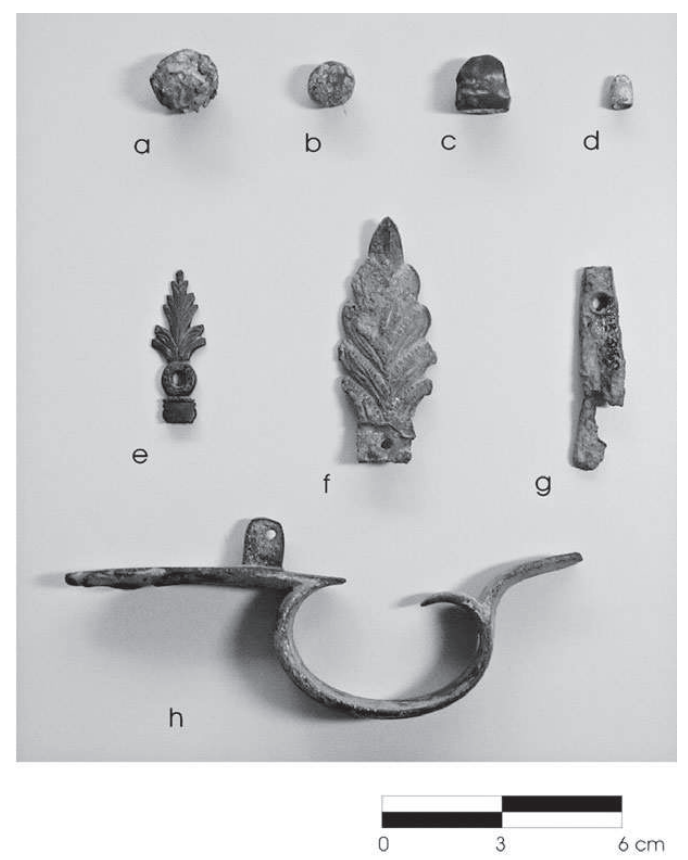

Figura 3: Artefatos ligados a armamentos encontrados nas senzalas a) bala cilíndrica de mosquete; b) bala cilíndrica de mosquete; c) bala de arma de percussão; d) bala cônica minie de arma de percussão; e-f) adornos de partes metálicas; g) componente metálico do mecanismo de acionamento; guarda mato (Fotografia: Marcos A. T. de Souza, 28/01/2008).

Uma categoria mais discreta associada à autonomia escrava liga-se aos itens empregados no transporte. Os materiais arqueológicos incluídos nessa categoria incluem oito fivelas de arreio e 24 cravos de ferradura. Uma explicação possível para a aparição desses itens no interior de senzalas fundamenta-se no relato do diplomata francês Barão de Forth-Rouen durante sua pernoite, em 1847, em um engenho baiano. Segundo ele, os escravos desse engenho, além de possuírem roças próprias, tinham seus próprios cavalos. Alguns chegavam até a alugar esses animais para o proprietário ${ }^{34}$. Isso sugere que os itens ligados ao transporte encontrados nas senzalas do engenho podiam se relacionar à posse de animais de cela, o que, em ultima instância, representaria um maior grau de autonomia dos escravos, tanto em termos de circulação quanto de capacidade produtiva.

Entre os artefatos encontrados nas senzalas estão alguns poucos, porém significativos, itens devocionais. Nessa categoria estão incluídos um fragmento de crucifixo e um cristal negro, ambos encontrados na área 11 e

\section{Maracanan}


representantes de práticas religiosas híbridas. Enquanto o primeiro remete-nos, a principio, à devoção católica, o outro sugere uma prática espiritual de origem africana que dotava tais objetos de poderes mágicos destinados à proteção espiritual. Esses cristais aparecem descritos em relatos de cronistas que passaram pelo Brasil ${ }^{35}$ e estão também presentes em sítios ocupados por escravos nas Américas ${ }^{36}$.

Um item incluído na categoria 'vestuário e adorno' poderia também ser agregado a esse grupo: as contas de colar que, em sua função simbólica, podiam conter uma série de significados e mensagens, incluindo status marital, faixa etária, gênero e orientação religiosa. Foram encontrados, no total, seis delas em todo o sítio: cinco na área 11 e uma no quintal da sede (Figura 4). Todas as contas encontradas nas senzalas foram oriundas da Europa, sua principal região produtora e deviam, também, ser adquiridos nos mercados locais ou, até mesmo, no engenho, onde Alves vendia a seus escravos coisas que são geralmente do agrado dos africanos ${ }^{37}$.

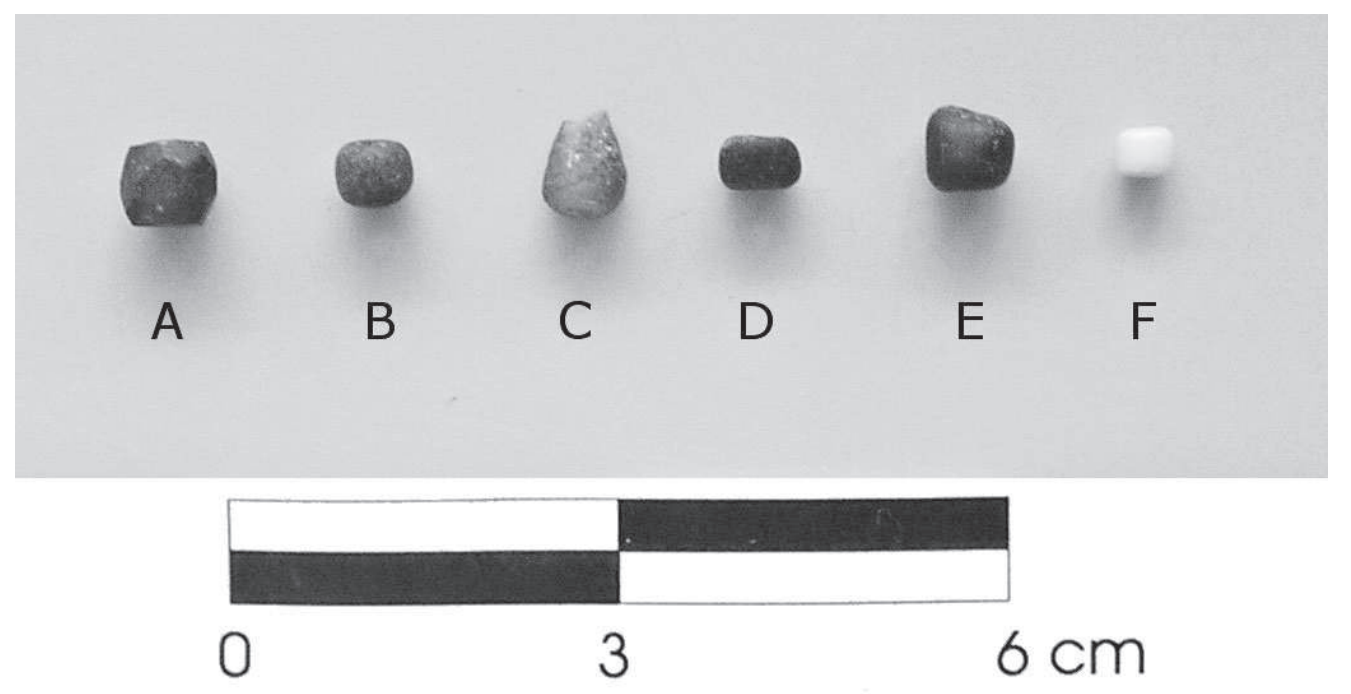

Figura 4: Contas de vidro da Área 11 (a-e) e do quintal da sede (F). A) Facetada, azul, provavelmente da Boemia, século XIX; B) Negra, opaca, provavelmente Veneziana; C) Vermelha, moldada, européia; D) Negra, opaca, provavelmente veneziana; E) Negra, opaca, provavelmente veneziana; F) Branca, européia (Fotografia: Marcos A. T. de Souza, 28/01/2008). 
Outros itens destinados a adornar o corpo somaram-se às contas, oferecendo-nos alguma idéia das escolhas feitas pelos escravos do engenho em relação à forma como se apresentavam. Eles incluíram um pente de prender cabelo em osso de tartaruga adornado com três pedras de vidro (Figura 5) e cinco discos de metal perfurado, um proveniente da área 11 e quatro da área 12 (Figura 6). Esses discos são feitos de metal reciclado e comumente encontrados em sítios históricos de Goiás. Embora seu uso específico seja desconhecido, podiam usá-los para formar colares, pingentes ou pulseiras. Alguns menores podiam ainda ser usados em brincos. Em escavações nos fundos das senzalas foi encontrado também um pequeno brinco ou pingente com a forma sinoidal. Outros itens de uso pessoal incluem fragmentos de cachimbo de argila, encontrados apenas na área 11, um alfinete e duas moedas.

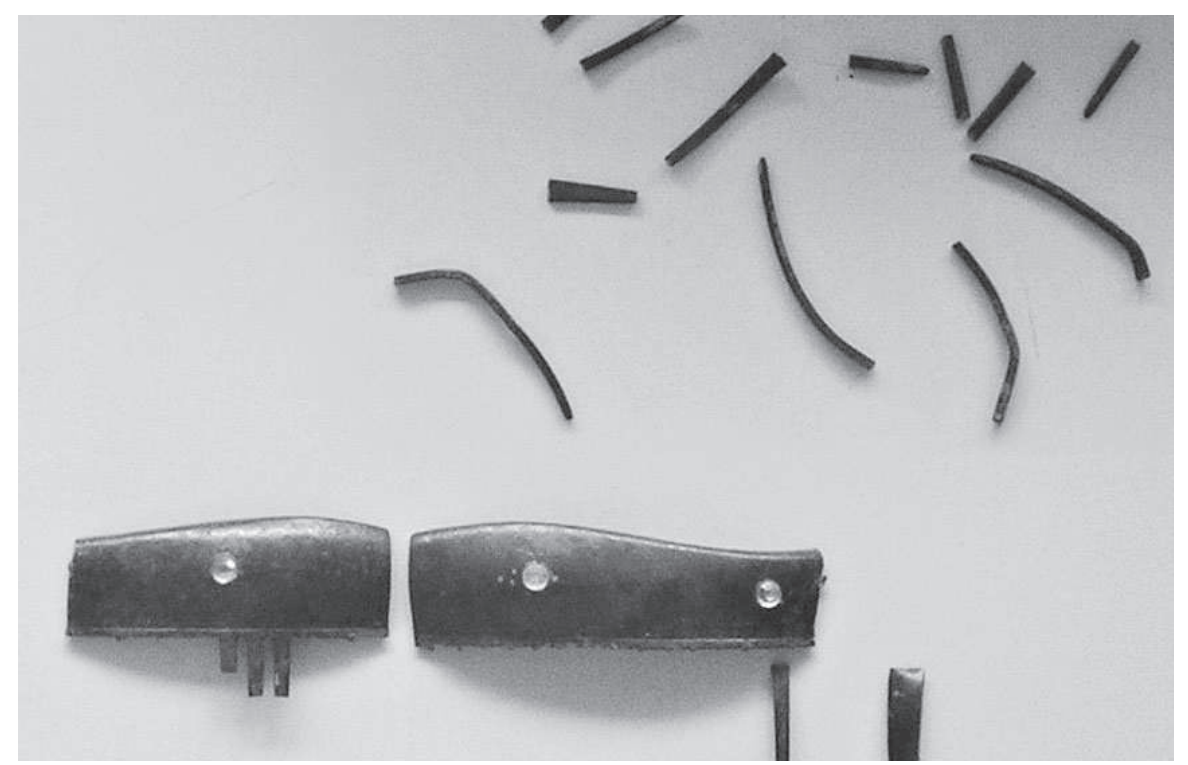

Figura 5: Pente de prender cabelo, Área 12 (Fotografia: Marcos A. T. de Souza, 28/01/2008).

Alguns dos artefatos encontrados no engenho podem ter obedecido a mais de uma função, o que é particularmente válido para o caso dos itens de vidros reciclados que eram formados por meio do lascamento de fragmentos de garrafas. Esses artefatos tinham um gume intencionalmente formado e podiam ser empregados para raspar, cortar ou perfurar. Outro grupo que podia ser usado em mais de uma função é o dos artefatos líticos. Esses artefatos estão

\section{Maracanan}


representados por quatro isqueiros, sete raspadores polidos e duas lascas de sílex de função não determinada. Os isqueiros apresentam-se, geralmente, em sílex lascado. Usados para produzir faíscas, podiam ser usados para ascender fogueiras e cachimbos. Interessante notar que todos os isqueiros foram encontrados na área 11, onde também apareceram cachimbos, sugerindo sua relação com o consumo do tabaco. Os raspadores líticos foram encontrados nas áreas 11 e 12. Esses objetos podem ter sido empregados nas mais diversas tarefas cotidianas, incluindo a trituração de sementes para alimentação, fins rituais ou preparação de fibras para cestaria. Assim como os vidros reciclados, a manufatura e uso desse conjunto de artefatos exigia a aplicação de conhecimentos tecnológicos específicos.

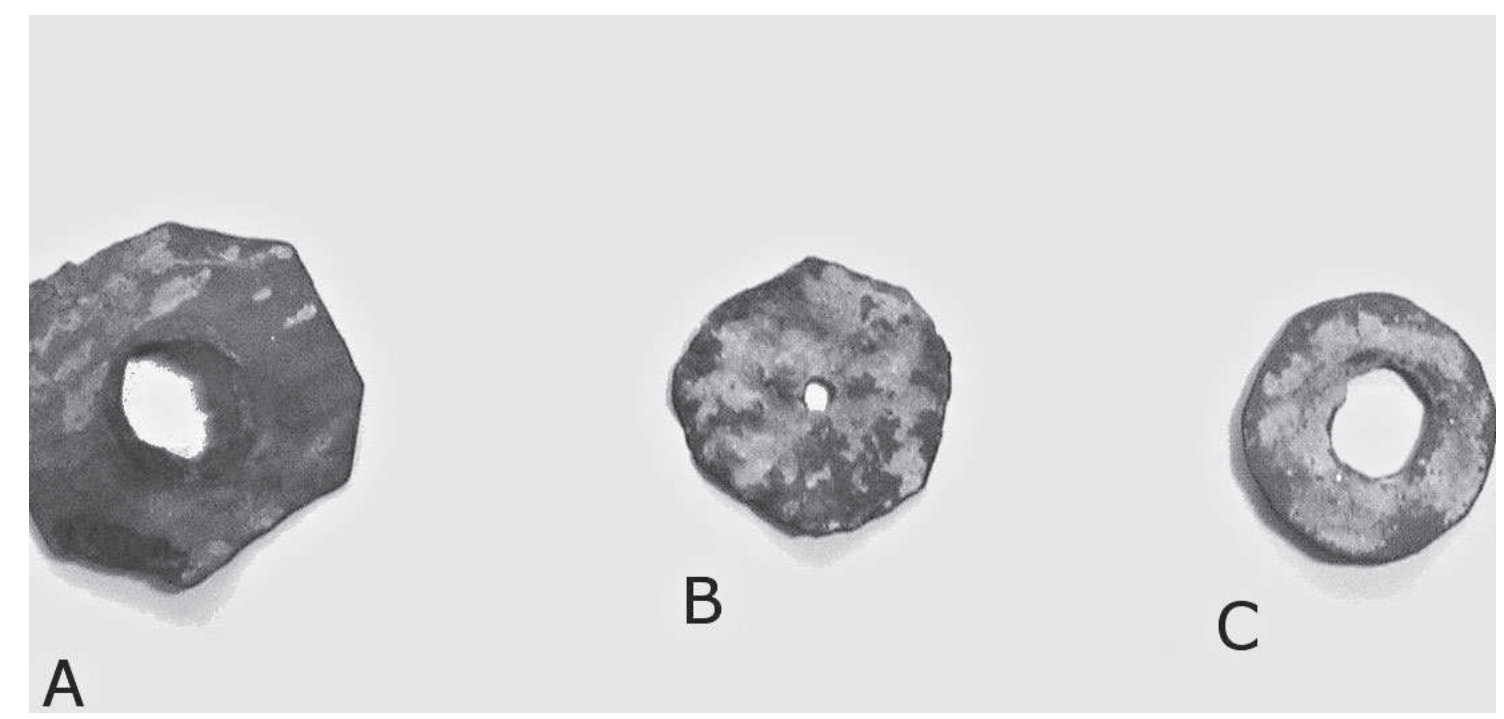

Figura 6: Adornos pessoais produzidos por reciclagem (Fotografia: Marcos A. T. de Souza, 29/01/2008).

Digno de menção é a falta de objetos ligados aos cuidados corporais no nível do piso das duas senzalas, que podiam incluir tanto os frascos medicinais quanto os de perfumaria. No material arqueológico proveniente da sede da fazenda, eles estão presentes, ainda que de forma austera, com percentuais oscilando entre 1 e 7\%. A ausência desses itens nas senzalas pode ser explicado pelo fato que, durante o século XIX, os escravos empregavam formas distintas de curar doenças, lançando mão da medicina popular e práticas mágico-religiosas. Em sua passagem por Goiás, por exemplo ${ }^{38}$, registrou que "os negros servem-se, em geral, de remédios baseados nas crendices que 
trouxeram da pátria, atravessando o mar, e que conservam zelosamente". Pode estar associado a esse tipo de prática, o cristal encontrado.

Do conjunto material escavado nas senzalas do engenho é possível obter-se um quadro da vida no seu interior. Ali se ocupavam os escravos das suas necessidades mais imediatas. À volta do fogo, podiam acender um cachimbo. Podiam costurar suas roupas, preparar e consumir sua refeição ao fim do dia. Bebiam alguma coisa. Ali também se adornavam. No espaço de cada cubículo, guardavam seus objetos de uso cotidiano, que podiam relacionar-se tanto a sua ocupação quanto a sua sobrevivência, incluindo as selas dos cavalos e armas. O registro arqueológico é incompleto e em decorrência disso, escapa-nos a chance de chegar a outros tantos fragmentos de um cotidiano precioso. Não é possível encontrar itens perecíveis, aqueles que não se preservam no registro arqueológico, tais como cestarias e tecidos. Não falta contudo a nossa percepção o fato de que o espaço de cada cubículo era complexo, envolvido em múltiplas possibilidades e formas de intervir no mundo.

Visto em seu conjunto, esse universo material apresenta-se, ao contrário do que se poderia supor, como bastante diversificado. Um exemplo disso está nos instrumentos empregados pelos habitantes das senzalas em três funções básicas da existência cotidiana: raspar, perfurar e cortar (Tabela 3). Nos três grupos, podiam os indivíduos lançar mão de diferentes recursos materiais. Podiam usar tanto o vidro lascado quanto o lítico polido, ambos os presentes nas duas áreas pesquisadas. Podiam ainda, contar, para as três funções, com instrumentos em metal, fossem facas ou canivetes, adquiridos no mercado ou em segunda mão.

Esse conjunto material não era só diversificado. Estava também envolvido em diferentes estratégias cotidianas. Uma primeira seria a aquisição de itens diretamente no mercado, ainda que em baixa escala, possível pela criação de uma economia informal. Uma segunda estratégia envolveria a aquisição de itens de segunda mão tanto junto aos senhores quanto entre os próprios escravos, uma suposição plausível considerando evidências desse sítio e de outros escavados no Centro-Oeste brasileiro. Uma terceira estratégia envolveria a produção própria de utensílios e ferramentas. Aqui podem ser incluídas as cestarias que, embora, comumente, não se preservem em solo brasileiro, foram amplamente produzidas pelos escravos no Brasil ${ }^{39}$. Junta-se

\section{Maracanan}


a esse grupo, as cerâmicas e ferramentas em pedra, que são passíveis de identificação via registro arqueológico e foram identificadas no Engenho de São Joaquim. Uma última estratégia, ainda, compreendia a reciclagem de itens industrializados, caso aqui exemplificado pelos vidros lascados e algumas peças em metal encontradas nas escavações.

$\mathrm{O}$ alto número de artefatos encontrados e a presença de um conjunto diverso de estratégias vai contra a premissa de que os escravos brasileiros viviam em um universo material limitado, uma percepção que emerge de critérios socialmente construídos no Mundo Moderno, tais como falta de mobiliário $^{40}$, falta de conforto doméstico ${ }^{41}$ e pobreza $^{42}$. Embora a escravidão tenha imposto indiscutíveis restrições à vida dos escravos, tais conceitos não parecem adequados quando nos referimos às condições materiais dos escravos.

Os artefatos usados no interior das senzalas e aqui descritos, muito além de representarem meras idiossincrasias, relacionavam-se à criação de nexos e sentidos para a existência dos seus usuários. Por meio do uso - e algumas vezes produção - desses artefatos, os escravos criaram mecanismos de diferenciação social em relação aos senhores. Basearam-se, por exemplo, em critérios distintos na escolha das decorações das louças e no ritual envolvido com o consumo de alimentos. Lançaram mão também de um aparato material que, em seu conjunto, destoava daquele usado nas residências da população livre. Nas senzalas, prevaleciam à diversidade e a flexibilidade.

As evidências indicam que os escravos que viveram no Engenho de São Joaquim desenvolveram mecanismos que lhes permitia compartilhar práticas específicas. Ns duas áreas investigadas, nota-se que eles adotaram formas semelhantes de consumir alimentos, se adornar e complementar sua dieta. Eles também compartilharam conhecimentos sobre tecnologias particulares, o que é visível pela semelhança com que, nas duas áreas, lascaram vidro ou produziram adornos de metal reciclado. Eles desenvolveram uma base comum para coexistir. Havia, todavia, espaço para a diferença. Por exemplo, foram identificados cachimbos apenas na área 11, enquanto o único item ligado ao corte e costura foi encontrado na área 12. Objetos ligados à prática espiritual estiveram presentes também apenas na área 11. Foi apenas nela que foram encontradas ainda contas de colar. Esses dados apontam para uma direção promissora no estudo das comunidades escravas aqui apenas superficialmente exploradas: a chance de identificarmos 
a criação de mecanismos de diferenciação entre indivíduos ou pequenas coletividades nas comunidades escravas.

\section{Conclusão}

Ao discutir os chamados 'espaços transicionais', Lang ${ }^{43}$ argumentou que a porta é, por excelência, um lugar de incerteza, um espaço do sim ou do não. A porta cria uma oposição entre dentro e fora, instala diferença. Nas vivências escravas, a porta das senzalas tinha uma função importante, servindo como um delimitador entre a vida exterior e a interior, entre um mundo dos outros e um mundo próprio. Assim como aconteceu em outros engenhos, os espaços das senzalas eram determinados pelo proprietário. Era ele o responsável por definir as características de cada residência, incluindo sua localização, limites, forma e aspecto. O mesmo, no entanto, não pode ser dito sobre sua vida interior. Embora limitados por um ambiente altamente normatizado, os escravos foram capazes de estruturá-lo de modo a atender suas necessidades, lançando mão, para isso, de referenciais por eles forjados.

Por meio da construção contínua das práticas materiais criadas e recriadas no interior das senzalas, os escravos que viviam no Engenho de São Joaquim tinham a oportunidade de alcançar ainda aquilo que Giddens ${ }^{44}$ denominou 'segurança ontológica', um estado de confiança obtido pelo indivíduo na sua identidade, capaz o suficiente de fazê-lo sentir-se seguro em relação à continuidade das suas experiências. Enquanto a escravidão solapava a liberdade e as chances de intervir no mundo, os envolvimentos nas ações cotidianas faziam que com as possibilidades fossem reinventadas, dentro de novos conjuntos de referência e a partir do estoque de conhecimento existente no próprio grupo. Assim, tinham a chance de alcançar certo nível de estabilidade cultural e social. Essa noção, vai de encontro ao que vêm propondo, na historiografia, autores como Florentino e Góes (1997:175), que se baseiam na idéia de que as relações estabelecidas no interior das senzalas pelas famílias escravas tinham uma função organizadora e estabilizante.

Giddens ${ }^{45}$ afirmou que "os atores sociais se movimentam em setores localizados, dentro de totalidades mais amplas e isso limita seu conhecimento. Por isso, as elites podem saber muito pouco sobre como vivem os menos privilegiados". É provável que Joaquim Alves, o proprietário do engenho, tivesse um conhecimento muito limitado acerca das motivações, interesses e

\section{Maracanan}


objetivos dos seus escravos. As práticas culturais e sociais passadas no interior das senzalas eram alheiam à vontade do seu senhor e, com isso, os escravos não só agiam sobre o mundo. Também exerciam uma forma de poder invisível aos olhos de Alves. Não o conhecido 'poder sobre', baseado na autoridade ou ameaça da força, mas o 'poder para', entendido como a capacidade que todo individuo tem de transformar o mundo material e social, o que liga-se fundamentalmente à produção e reprodução do conhecimento ${ }^{46}$. 
Notas e Referências

1 Richard LANG. "The dwelling door: towards a phenomenology of transition". In: David SEAMON; Robert MUGERAUER (eds.). Dwelling, place, and environment. 2a edição. Florida: Krieger Publishing, 2000, pp. 201-213.

2 Theresa SINGLETON; Marcos André Torres de SOUZA. "Archaeologies of the African Diaspora: Brazil, Cuba, United States". In: Teresita MAJEWSKI; David GAIMSTER (eds.). International Handbook of Historical Archaeology. New York: Springer, 2009, pp. 449-469.

3 Marcos André Torres de SOUZA. Spaces of difference: An archaeology of slavery and slave life in a 19th Century Brazilian Plantation. Tese de doutorado. Syracuse University, Department of Anthropology, 2010.

4 Marcos André Torres de SOUZA. "Uma outra escravidão: a paisagem social no Engenho de São Joaquim, Goiás”. Vestígios: Revista Latino-Americana de Arqueologia Histórica, Belo Horizonte: UFMG, v. 1, n. 1, 2007, pp. 61-92.

5 Idem p. 83-85

6 Idem p. 83-85

7 Luiz D'AlinCOURT. Memória sobre a viagem do Porto de Santos à Cidade de Cuiabá. São Paulo: Editora da Universidade de São Paulo, 1953; Johann E POHL. Viagem no interior do Brasil. Belo Horizonte: Itatiaia, 1978; Auguste de SAINT-HILAIRE. Viagem à Província de Goiás. Belo Horizonte: Itatiaia, 1975.

8 Tim INGOLD. The perception of the environment. London: Routledge, 2000.

9 Douglas V ARMSTRONG; Kenneth G. KELLY. "Settlement patterns and the origins of African Jamaican Society: Seville Plantation, St. Ann's Bay, Jamaica". Ethnohistory: 2000, v. 74, n. 2, pp. 369-395, 2000.

10 Marcos André Torres de SOUZA. Op. cit., 2007, p. 83-89.

11 James DEETZ. In the small things forgotten: An Archaeology of Early American Life. New York: Doubleday, 1988.

12 Leila M.ALGRANTI. "Famílias e vida Doméstica”. In: Laura de M. e SOUZA (org.). História da vida privada no Brasil, vol. I. São Paulo: Companhia das Letras, 1997, pp. 83-154; Emanuel ARAÚJO. O Teatro dos vícios. Rio de Janeiro: José Olympio, 1993.

13 Charles RiBEYROLlES. Brasil Pitoresco. São Paulo: Livraria Martins.

\section{Maracanan}


14 John M.VLACH. “'Snug Li'l House with flue and oven': Nineteenth-century reforms in plantation slave housing". Perspectives in vernacular architecture., v. 5, 1995, pp. 119-129.

15 Mary DOUGLAS. Purity and danger. Reimpressão. London: Routledge, 2002.

16 Laurence DOUNY. The materiality of domestic waste: the recycled cosmology of the Dogon of Mali. Journal of Material Culture, v. 12, n. 3, 2005, pp. 309-331.

17 Merrick POSNANSKI. "West Africanist reflections on African-American Archaeology"; In: Theresa A. SINGLETON (Ed.). "I, too, am America": archaeological studies of African-American life. Charlottesville: Smithsonian Institution Press, 1999, pp. 21-37.

18 Hermenegildo CAPELLO; Roberto R. IVENS. From Benguela to the Territory of Yacca. New York: Negro University Press, 1969; Alexandre MALHEIRO. Chronicas do Bihé. Lisboa: Livraria Ferreira, 1903.

19 Luiz D’ALINCOURT. Op.cit., p. 91; Johann E POHL. Op.cit., p. 289; Auguste de SAINT-HILAIRE. Op. cit., p. 91.

20 Nicholas DAVID. "The Fulani Compound and the Archaeologist". World Archaeology. 1971, v. 3, n. 2, pp. 111-131; Christopher R.DECORSE. An Archaeology of Elmina. Washington: Smithsonian Institution Press, 2001.

21 Idem. p. 114.

22 James DEETZ. "Material culture and world view in Colonial AngloAmerica". In: Mark LEONE; Parker POTTER JR. (eds.). The recovery of meaning: Historical Archaeology in the Eastern United States. Washington D.C.: Smithsonian Institution Press, 1988, pp. 377-504.

23 Christopher R. DECORSE. Op. cit., p.178.

24 Luis C. P. SYMANSKI, Marcos A. T. de SOUZA. "O registro arqueológico dos grupos escravos: questões de visibilidade e preservação". Revista do Patrimônio Histórico e Artístico Nacional, Rio de Janeiro: IPHAN, volume temático "Patrimônio Arqueológico: o Desafio da Preservação", v. 33, 2007, pp. 215-243.

25 George L.MILLER. Classification and economic scaling of 19th Century Ceramics. Historical Archaeology,1980, v. 14, pp. 1-41.

26 Laurie.WILKIE. Culture bought: evidence of creolization in the consumer goods of an Enslaved Bahamian Family. Historical Archaeology, v. 34, n. 3, 2000, pp. 10-26.

27 Luis C. P. SYMANSKI, Marcos A. T. de SOUZA. Op. cit., p. 230. 
28 John S. OTTO. Status differences and the archaeological record: a comparison of planter, overseer, and slave sites from Cannon's Point Plantation, St. Simons Island, Georgia. Tese de doutorado. University of Florida, Department of Anthropology, 1975.

29 B. J. BARICKMAN. "“A bit of land, which they call roça”: slave provision grounds in the Bahian Recôncavo, 1780-1860". The Hispanic American Historical Review, v. 74, n. 4, 1994, pp. 649-687; Stuart B. SCHWARTZ. Escravos, roceiros e rebeldes. Bauru: Edusc, 2001.

30 Johann E. POHL. Op.cit., p. 289; Auguste de SAINT-HILAIRE. Op. cit., p. 99.

31 Ira BERLIN; Philip D.MORGAN. "Introduction”. In: Ira BERLIN; Philip D.MORGAN (eds.). Cultivation and culture. Charlottesville: University Press of Virginia, 1993, pp. 1-48.

32 Mary KARASCH. "Slave women on the Brazilian Frontier in the 19th Century". In: David B. GASPAR; Darlene C. HINE (eds.). More than a chattel: black women and slavery in the Americas. Bloomington: Indiana University Press, 1996. pp. 79-96.

33 Raymundo J. da C.MATTOS. Chorographia Histórica da Província de Goiás. Goiânia: Governo de Goiás, 1978.

34 B. J. BARICKMAN. Op. cit., p. 661.

35 Thomas EWBANK. Life in Brazil. New York: Brothers Publishers, 1856.

36 Laurie WILKIE. "Secret and sacred: contextualizing the artifacts of AfricanAmerican magic and religion". Historical Archaeology, 1997, v. 31, v. 4, pp. 81-106.

37 Auguste de SAINT-HILAIRE. Op. cit., p. 89.

38 Johann E POHL. Op.cit.,126.

39 Luiz MOTT. "Subsídios à história do pequeno comércio no Brasil”. Revista de História, 1978, v. 53, n. 105, pp. 81-106; Luciano FIGUEIREDO. O avesso da memória: cotidiano e trabalho da mulher em Minas Gerais no Século XVIII. Rio de Janeiro: José Olympio, 1993; Camilla AGOSTINI; Aline MAZZA. "“Vive de fazer louça": um estudo sobre produção artesanal e mudança em contextos dos séculos XIX e XX”. Paper, apresentado no Congresso Internacional de Arqueologia Moderna, Lisboa, abril de 2011; para Goiás, ver Mary KARASCH. Op. cit., p. 85-89.

40 ALGRANTI, Leila M. Op. cit., p.110.

41 Mary KARASCH. Op. cit., p.183-184.

\section{Maracanan}


42 Emanuel ARAÚJO. Op. cit., p. 77-78.

43 LANG, Richard. "The dwelling door: towards a phenomenology of transition". In: David SEAMON; Robert MUGERAUER (eds.). Dwelling, place, and environment. 2a edição. Florida: Krieger Publishing, 2000, pp. 201-213.

44 Anthony A. GIDDENS. A constituição da sociedade. São Paulo: Martins Fontes, 1989.

45 Anthony A. GIDDENS. Op. cit., p. 76.

46 Daniel MILLER; Christopher TILLEY. "An Introduction”. In: Daniel MILLER; Christopher TILLEY (eds.). Ideology, power and prehistory. Cambridge: Cambridge University Press, 1984, pp. 1-15.

Janeiro | Dezembro 2011 